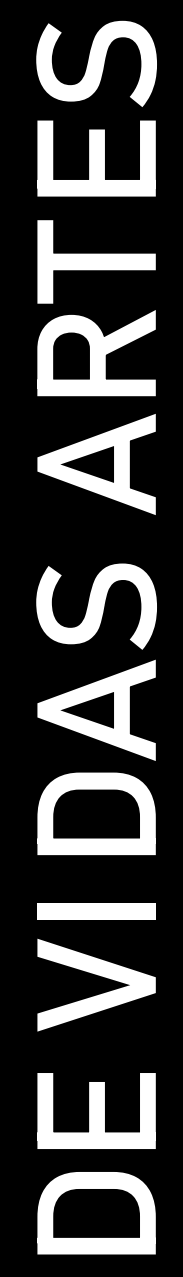

PAULA GUERRA E LÍGIA DABUL (EDS.) 


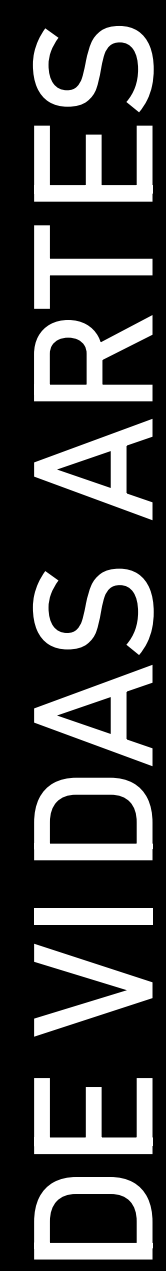

\section{PAULA GUERRA E LÍGIA DABUL (EDS.)}

Design por Irandina Afonso

Ilustração da Capa por Lua Celina

Publicado em Setembro 2019

Universidade do Porto. Faculdade de Letras

[University of Porto. Faculty of Arts and Humanities]

Porto, Portugal

ISBN 978-989-8969-18-7

Suporte: Eletrónico - Formato: PDF / PDF/A 


\title{
IV.3. Do ethos à praxis. Carreiras DIY na cena musical independente em Portugal
}

\section{IV.3. From ethos to praxis. DIY Careers in the Independent Music Scene in Portugal}

\section{Ana Oliveira}

\section{Resumo}

O presente capítulo aborda a temática da profissionalização na música, explorando as relações entre independência, carreiras DIY e sustentabilidade económica. A análise parte de um dos valores centrais da subcultura punk, o ethos DIY, que aqui surge como um novo padrão de promoção da empregabilidade, permitindo gerir o risco e a incerteza associados à construção de carreiras na música. Centrando-nos na cena musical independente das áreas metropolitanas de Lisboa e Porto, procuramos compreender o que é hoje ser músico em Portugal e que estratégias são mobilizadas pelos artistas na gestão das suas carreiras. Com base em entrevistas semiestruturadas a diferentes atores da cena musical independente, discutimos diferentes formas de manifestação do DIY nas suas trajetórias profissionais, concluindo que este assume hoje, essencialmente, um caráter pragmático, estando presente enquanto estratégia de sobrevivência na música.

Palavras-chave: trabalho criativo, carreiras na música, DIY, música independente.

\begin{abstract}
This chapter addresses the professionalization in music, exploring relationships between independence, DIY careers and economic sustainability. The analysis is based on one of the core values of the punk subculture, the DIY ethos, which emerges here as a new standard of employability promotion, allowing managing the risk and uncertainty associated with building careers in music. Focusing on the independent musical scene of the metropolitan areas of Lisbon and Porto, we try to understand what it means nowadays to be a musician in Portugal and what strategies are mobilized by the artists to manage their careers. Based on semi-structured interviews with different actors of the independent music scene, we discuss different forms of DIY manifestation in their professional trajectories, concluding that DIY is essentially pragmatic, being present as a strategy to survive in the music field.
\end{abstract}

Key words: creative work, music careers, DIY, independent music.

\section{Entrada}

A crise internacional de 2008 , originada no centro do sistema financeiro norteamericano, com reflexos na crise da dívida soberana europeia, fez com que vários países da zona Euro se vissem forçados a pedir ajuda financeira externa. Em maio de 2011, Portugal foi um desses países. Desde então e até maio de 2014, o país esteve sujeito a um programa de ajustamento alicerçado num pesado pacote de austeridade fiscal e numa sequência de reformas orientadas, quer para a redução dos custos de mão-de-obra e das despesas 
públicas, quer para a desregulamentação do mercado de trabalho. Como consequência, durante esse período, um dos problemas sociais que se intensificou à escala nacional foi o desemprego. Segundo o Instituto Nacional de Estatística, em dezembro de 2014 a taxa de desemprego total era de $13,4 \%$. No caso da população jovem os números eram ainda mais preocupantes. No mesmo período, e considerando a população entre os $15 \mathrm{e}$ os 24 anos, a percentagem subia para os $34,5 \%$. Paralelamente, o clima de austeridade fez-se sentir igualmente na cultura. Por um lado, num plano económico, com cortes nas verbas disponibilizadas no âmbito do orçamento do Estado. E, por outro, num plano simbólico, com a extinção do Ministério da Cultura, em 2011, reduzido à categoria de Secretaria de Estado.

Era este o cenário quando em 2014 começámos a construir este projeto de investigação ${ }^{202}$. A par deste contexto de austeridade, crescimento dos níveis de desemprego, aumento da precariedade no mercado de trabalho, e desvalorização da cultura, a escassez de trabalhos científicos em torno da construção de carreiras no âmbito do trabalho criativo, e mais especificamente da música, motivou o surgimento deste projeto. Almejamos desde o início não apenas aprofundar o conhecimento sobre a atual configuração do campo da música independente, mas também e sobretudo contribuir para a discussão que mais recentemente começa a ser feita em torno do trabalho criativo e da construção de carreiras na música. Quais as especificidades da construção de uma carreira na música independente? 0 que significa ser músico em Portugal e que estratégias são mobilizadas por parte dos diferentes intervenientes na cena musical no sentido de alcançar a sua sustentabilidade económica? Até que ponto estão presentes os princípios e lógicas de trabalho do-it-yourself (DIY)? Focando-nos na cena de música independente portuguesa, procuraremos dar resposta a estas questões.

\section{A abordagem DIY na análise das carreiras musicais: um enquadramento}

A análise das cenas musicais em contexto urbano tem-se focado, tradicionalmente, nas práticas de produção musical sem considerar as formas

\footnotetext{
202 A investigação em que se enquadram os resultados discutidos neste capítulo resulta da frequência, por parte da autora, do Programa Doutoral de Estudos Urbanos do ISCTE-IUL - Instituto Universitário de Lisboa e da Faculdade de Ciências Sociais e Humanas da Universidade Nova de Lisboa. A autora encontra-se a desenvolver a sua tese de doutoramento intitulada "Do It Together Again: redes, fluxos e espaços na construção de carreiras musicais na cena indie portuguesa". A investigação é financiada pela Fundação para a Ciência e a Tecnologia e supervisionada pela Professora Doutora Paula Guerra.
} 
pelas quais estas estão ancoradas nas dinâmicas organizacionais e económicas que caracterizam atualmente a economia cultural. Associando a nossa voz à de outros autores (ver por exemplo Tarassi, 2018), defendemos a necessidade de um alargamento da compreensão das formas de produção musical contemporâneas, no sentido da consideração da dimensão profissional da atividade musical. Ou seja, urge olhar para a produção musical como uma atividade profissional e profissionalizada, que requer um conjunto de competências que vão muito para além da técnica musical e que englobam capacidades de gestão e negociação, como uma qualquer outra carreira profissional. Importa, igualmente, atender à sustentabilidade económica das práticas de produção musical e às estratégias para tal mobilizadas, bem como às condições de vida dos músicos e dos diferentes atores que compõem o campo musical.

Com efeito, e no que concerne ao trabalho criativo, temos assistido nas últimas décadas a um considerável aumento do interesse científico pela construção de carreiras. Destacamos, a título de exemplo, o trabalho de Leadbeater \& Oakley (1999), que traçam o perfil dos empreendedores culturais de quatro cidades da Grã-Bretanha, identificando as suas formas de trabalho. Também no contexto britânico, e sobretudo no que à indústria da moda diz respeito, Angela McRobbie (1999, 2004, 2016) tem dado importantes contributos para a compreensão das formas de trabalho na chamada nova economia criativa. Adotando um posicionamento crítico, analisa-as a partir do contexto de austeridade, incerteza e precariedade que caracteriza atualmente o mercado de trabalho, com especial intensidade no caso dos jovens. Reportando-se, igualmente, ao trabalho criativo jovem, Miranda Campbell (2013) analisa diferentes exemplos de empregos criativos de pequena escala e autogeridos, dando conta dos processos de "navegação" e "negociação" encetados por jovens canadianos na sua transição para a vida adulta.

Semelhante interesse tem surgido quando consideramos especificamente a música. Vários autores têm-se focado na construção e estruturação de carreiras musicais, dando especial atenção às condições de vida dos músicos e às estratégias mobilizadas pelos mesmos no sentido de alcançar a sua sustentabilidade económica. São disso exemplo trabalhos como os de Oliver (2010), que dão conta da importância das novas ferramentas tecnológicas na busca da auto-suficiência por parte dos músicos, nomeadamente no âmbito dos processos criativos e de gestão em que estes 
se envolvem. Reportando-se à realidade austríaca, Rosa Reitsamer e Rainer Prokop (Reitsamer \& Prokop, 2018; Reitsamer, 2011) analisam os processos de construção e estruturação das carreiras de DJs de techno e de drum'n'bass, bem como de músicos da cena rap, mostrando como estes artistas underground gerem as suas próprias carreiras de modo flexível, autoresponsável e adotando uma postura DIY. No contexto francófono, Marc Perrenoud e Pierre Bataille (2017) têm desenvolvido trabalhos sobre as cenas musicais francesa e suíça, identificando diferentes formas de ser músico, consoante as condições de vida dos artistas e as suas diferentes fontes de rendimento.

Os trabalhos referidos têm em comum uma mesma linha condutora que é também a nossa. As análises desenvolvidas baseiam-se numa abordagem DIY das trajetórias profissionais ou das carreiras destes atores sociais. Focando-nos na música, tal abordagem radica na premissa de que esta é um polo aglutinador de várias atividades, podendo a produção musical ser analisada a partir de uma perspetiva empreendedora em relação aos músicos. Vários autores têm desenvolvido trabalho sobre estes "novos independentes"(Leadbeater \& Oakley, 1999), trabalhadores freelancers, protagonistas de uma lógica de desenvolvimento de competências múltiplas, que os faz assumir simultaneamente papéis vários e complementares - 0 papel de músicos, produtores, designers, promotores -, gerando interseções entre vários subsetores artísticos e criativos, e também questionando fronteiras entre o profissional e o amador (Hennion, Maisonneuve, \& Gomart, 2000).

Esta ênfase assenta na revisitação por parte da teoria social de um dos valores centrais da subcultura punk - o ethos DIY (Dale, 2008, 2010; Guerra, 2017, 2018; Hein, 2012; McKay, 1998; Moran, 2010; Oliver, 2010), assente numa lógica de empowerment, na posse dos meios de produção pelos próprios músicos como uma alternativa aos circuitos de produção tradicionais e mainstream. Ainda que a noção de práticas de produção musical DIY tenha as suas raízes na década de 1950, com a emergência do rock'n'roll, é no final da década de 70, com o romper do movimento punk, que o termo atinge o seu expoente máximo (Bennett, 2018). Seguindo as linhas lançadas pela Internacional Situacionista ${ }^{203}$, nos anos de 1950 , e desiludidas

\footnotetext{
203 Recorde-se que a Internacional Situacionista foi um movimento de cunho político, cultural e artístico, pautado pela sátira e denúncia das contradições da sociedade capitalista, através da criação de objetos
} 
com o que entendem ser uma indústria musical distante e orientada para o lucro, as bandas punk propõem a criação de plataformas alternativas para a produção e distribuição de música, criando pequenas editoras independentes, responsáveis pela produção e distribuição dos primeiros álbuns de artistas punk e new wave (Laing, 1985). De um modo de produção musical simbólica e ideologicamente distinto dos circuitos comerciais da indústria da música, durante as décadas de 1980 e 1990, o ethos DIY manteve-se fortemente ligado à estética punk, mas alargou-se também a outros domínios socioculturais, que incluem áreas como o ambiente, os direitos dos animais, a pobreza ou o racismo (McKay, 1998).

Como Bennett (2018) defende, a conceptualização da noção de carreira DIY pressupõe compreendê-la enquanto uma forma de trajetória profissional, que parte da necessidade de gerir os "efeitos patológicos", tanto a nível político como económico, da pós-industrialização e, consequentemente, o risco e a incerteza que caracterizam as sociedades contemporâneas. Num contexto como aquele em que vivemos - a sociedade de risco (Beck, 1992) - não só os percursos biográficos são mais incertos e imprevisíveis, como os processos se tornam cada vez mais individualizados, sendo os atores sociais impelidos a criar as suas próprias trajetórias. As práticas culturais DIY surgem assim como resposta a este contexto, afirmando-se enquanto expressão cultural criativa e materializando-se também em práticas económicas culturais - economias culturais DIY.

Neste sentido, Bennett e Guerra (2019) chamam a atenção para o facto de se, por um lado, o conceito de carreira DIY permanece ligado às dimensões originais do ethos DIY e à busca de uma independência, por outro, atualmente, a este ethos soma-se um reconhecimento da necessidade de alcançar um estilo de vida sustentável, no qual não mais fazem sentido noções, anteriormente tidas como garantidas, como a de uma carreira estável e um salário constante. $\mathrm{Na}$ verdade, considerando as alterações socioeconómicas dos últimos 20 anos, protagonizadas pelos países desenvolvidos, Standing (2011) defende que tais mudanças criaram um novo tipo de categoria social - os precários ${ }^{204}$. Trata-se de pessoas (incluindo muitos jovens) que vivem e trabalham em condições precárias porque dependentes de oportunidades de emprego de curta duração, que poucas ou

artísticos contraculturais e da utilização de novas formas de comunicação, como os manifestos (Debord, 1967; Plant, 2002).

${ }^{204} \mathrm{Na}$ versão original usa-se o termo 'precariat'. 
nenhumas oportunidades de desenvolvimento de uma carreira estável oferecem. Torna-se frequente a navegação entre diferentes empregos em part-time e de curta duração como forma de obter os rendimentos necessários. Tal situação faz com que muitas pessoas mobilizem as suas competências, muitas vezes adquiridas informalmente, no sentido de construir carreiras DIY. Trata-se da mobilização de competências DIY, de resistência, realização, liberdade e ação coletiva como um novo padrão de promoção da empregabilidade. Não obstante, ainda que as carreiras DIY sejam elas próprias trajetórias precárias, importa salientar que se trata de uma precariedade escolhida reflexivamente e não imposta. Aliás, esta questão leva-nos a considerar a importância do background familiar, ou seja, a origem de classe destes atores enquanto elemento potenciador do seu envolvimento em carreiras DIY sustentáveis (Bennett, 2018; Threadgold, 2018).

Neste sentido, podemos entender as carreiras DIY como modos alternativos de trabalho, assentes em conhecimento adquirido pela prática e, frequentemente, pela participação em (sub)culturas juvenis. Com efeito, recentemente, o papel das experiências (sub)culturais juvenis na vida adulta dos seus participantes tem merecido maior atenção do ponto de vista académico. Focando-se na cena musical independente de Newcastle, na Austrália, e mobilizando conceitos bordieusianos como o de habitus e o de reprodução, Threadgold $(2015,2018)$ evidencia formas através das quais o ethos e as práticas DIY, ou por outras palavras o capital subcultural, são transformados e traduzidos em carreiras e escolhas profissionais. $\mathrm{O}$ autor considera a transferência de capitais como um processo essencial para a transformação das competências e disposições adquiridas através das experiências subculturais em carreiras DIY, permitindo a gestão de riscos e oportunidades de uma existência precária.

No contexto português, e no que a o movimento punk diz respeito, Paula Guerra $(2017,2018)$ aborda as manifestações do ethos DIY no quotidiano de atores sociais que pertencem e/ou pertenceram à cena punk. Mais concretamente defende a presença do DIY no reclamar de autenticidade do movimento e nas profissões e carreiras em que estes atores estão hoje envolvidos, demonstrando que as experiências (sub)culturais se alargam e transformam na vida adulta ao invés de conhecerem um fim abrupto com o final da juventude.

Ross Haenfler (2018) tem também discutido as formas de tradução de experiências musicais subculturais em competências profissionais e 
oportunidades de emprego, sem esquecer que este exercício é fortemente condicionado por questões de género, classe e raça. Focando-se no movimento straight edge e na cena musical hardcore nos EUA, Haenfler demonstra que muitos dos straight edgers mais velhos escolheram ou criaram as suas próprias carreiras, assentes em valores DIY partilhados no âmbito da sua experiência subcultural. Designa-os, por isso, como empreendedores subculturais. Paralelamente, o autor defende que as experiências subculturais encorajam disposições benéficas a uma postura empreendedora e ao mundo do trabalho mais "convencional": tolerância ao risco, confiança, autosuficiência, capacidade de adaptação, forte ética de trabalho, capacidade de alcançar objetivos ultrapassando obstáculos. Admite igualmente que, ao basear-se numa aprendizagem por tentativa e erro, o conhecimento prático, experiencial e informal adquirido nas cenas subculturais, muitas vezes, serve melhor o desenvolvimento de competências profissionais quando comparado com a formação e a educação formais. Ou seja, considera haver uma transformação das experiências subculturais em competências úteis no mercado de trabalho, como sejam as capacidades de gestão, organização e marketing.

Com efeito, assiste-se hoje ao crescimento dos níveis de profissionalização e empreendedorismo que caracterizam grande parte da esfera de produção cultural DIY contemporânea (Bennett, 2018; Tarassi, 2018). Reflexo deste fenómeno é a proliferação de Websites que procuram manter e promover o ethos DIY na produção musical, fornecendo ao mesmo tempo sugestões e conselhos sobre como tornar as carreiras musicais mais sustentáveis e profissionais ${ }^{205}$. As profundas alterações vivenciadas no âmbito da indústria da música e da economia criativa conduziram a uma redefinição das relações existentes no espetro da produção musical independente. Esta vive hoje um processo de profissionalização e institucionalização, o que implica uma redefinição das suas fronteiras e relações face à indústria musical mainstream. Na verdade, parece ser mais correto assumir que as práticas musicais DIY e independentes contemporâneas coexistem com as práticas mainstream num continuum e numa vasta dinâmica de interseção, gerando diferentes graus e formas de independência. Como Tarassi (2011 e 2018) dá conta na sua análise sobre a

205 É disso exemplo o website DIY Musician: https://diymusician.cdbaby.com/. E sobre este assunto importa evidenciar a relevância da tecnologia digital na criação de possibilidades de criação, produção e disseminação de música e também na própria formatação de carreiras DIY. 
cena musical independente de Milão, tal gera tensões culturais e fragmentação dentro da cena, bem como conflitos no que concerne a definições e delimitações e à legitimação simbólica do campo (Bourdieu, 1993).

Perante este cenário de redefinição do conceito de produção musical DIY e da esfera das práticas criativas DIY, alguns autores (ver por exemplo Jian, 2018; Threadgold, 2018) chegam a falar da cooptação do conceito DIY. Jian alerta mesmo para o perigo de celebrar em demasia esta "onda" das carreiras DIY, ressalvando que estas rapidamente se podem tornar numa "conspiração inconsciente e involuntária neoliberal" (Jian, 2018: 237), que encoraja as pessoas a viver em situações de precariedade, instabilidade e auto-exploração. Voltaremos a esta discussão no final do capítulo, depois de apresentados os principais resultados do trabalho de campo.

\section{Metodologia}

A análise aqui desenvolvida é fruto de um trilho metodológico qualitativo, alicerçado na informação recolhida através da realização de 70 entrevistas semi-diretivas a diferentes intervenientes na cena musical independente: músicos, produtores, editores, promotores, agentes, programadores/curadores de espaços de concertos, críticos/jornalistas e radialistas. O eleger das entrevistas como principal fonte de informação baseia-se no princípio sociológico de que o conhecimento reflexivo dos atores sociais é, em si mesmo, um recurso para a reconstrução científica e contribui para uma melhor compreensão dos fenómenos.

As entrevistas foram realizadas entre maio de 2016 e março de 2018 , sendo a amostra construída a partir da abordagem de "amostragem teórica" (Glaser, B. e Strauss, 1967) e da técnica de bola de neve. Isto é, a nossa amostra foi construída com base na sua relevância para a abordagem e as categorias teóricas adotadas na investigação. Partimos de um conjunto de informantes privilegiados e atores chave na cena musical independente portuguesa, previamente identificados, que facilitaram a entrada no terreno e permitiram a identificação de outros membros da cena musical a entrevistar. A cada novo entrevistado foi pedido que sugerisse outras pessoas a entrevistar, partindo também do pressuposto de que este exercício de nomeação providencia desde já informação relevante no que concerne às redes relacionais que consubstanciam a cena musical independente em Portugal. Na realização das entrevistas adotámos a abordagem de histórias de vida (Bertaux, 1997), no sentido de obter uma descrição tão detalhada 
quanto possível relativamente às trajetórias de vida dos entrevistados. As entrevistas foram posteriormente transcritas e analisadas com recurso aos softwares f4transkript e NVivo, respetivamente ${ }^{206}$.

Delineando um breve retrato sociodemográfico dos entrevistados, salientamos que do conjunto total de entrevistas, 40 foram realizadas com atores do campo musical baseados na Área Metropolitana de Lisboa e 30 na Área Metropolitana do Porto. Relativamente ao género dos entrevistados, estes são na sua maioria do género masculino, com apenas $21 \%$ dos entrevistados pertencendo ao género feminino. Na verdade, esta distribuição procurou ser representativa do campo musical em análise que, como identificado noutros trabalhos, é maioritariamente masculino (Guerra, 2013). Em termos etários, a maioria dos entrevistados (51\%) situa-se entre os 29 e os 39 anos. Sendo igualmente nosso objetivo envolver na investigação membros da cena independente em diferentes momentos das suas carreiras, os restantes entrevistados situam-se entre os 18 e os 28 anos (24\%), e entre os 40 e os 61 anos (também 24\%).

Do ponto de vista daquele que é o seu atual lugar de classe ${ }^{207}$, salientamos que a maioria dos entrevistados pertence a uma classe média e educada (à exceção de sete entrevistados, todos os restantes completaram ou frequentaram o Ensino Superior), associada a profissões liberais (no caso de 64\%), nas áreas artísticas, intelectuais ou científicas. Esta vantagem no que concerne à posse de capital económico, social e educacional estava já presente nas famílias de origem. Com efeito, $53 \%$ no caso das mães e $60 \%$ no caso dos pais dos entrevistados completaram ou frequentaram o Ensino Superior; $49 \%$ dos entrevistados têm pais com profissões intelectuais e científicas e em $14 \%$ dos casos os pais dos entrevistados são empresários ou proprietários. Estes dados vão, pois, ao encontro do que Bennett (2018) e Threadgold (2018) salientam a respeito da importância do background socioeconómico familiar no potenciar de carreiras DIY na música e noutras áreas criativas. Este é também um retrato semelhante àquele que foi feito a

\footnotetext{
${ }^{206}$ Ao longo do capítulo utilizaremos excertos das entrevistas como forma de ilustração das ideias discutidas. Pautando a nossa investigação pelos princípios da privacidade e da confidencialidade defendidos pelo Código Deontológico da Associação Portuguesa de Sociologia, mantemos o anonimato dos entrevistados, substituindo o seu nome verdadeiro por nomes fictícios.

207 Na construção dos lugares de classe, seguimos e adaptámos a Matriz ACM como evidenciamos em Abreu et al., 2017. A identificação dos lugares de classe resulta do cruzamento dos dez grupos profissionais patentes na Classificação Portuguesa das Profissões de 2010 com a situação na profissão dos entrevistados. Nos casos em que este cruzamento gerou dúvidas quanto à classificação dos indivíduos, foi considerado o nível de escolaridade dos mesmos, por sua vez categorizado segundo a International Standard Classification of Education de 2011 (UNESCO, 2012).
} 
respeito da cena punk em Portugal (Abreu et al., 2017). Por fim, no que concerne às suas profissões e papéis desempenhados na cena remetemos 0 leitor para a secção seguinte, na qual se analisará de forma mais aprofundada esta dimensão.

\section{Que músico ser, eis a questão! ${ }^{208}$ Representações sobre a condição de músico no Portugal contemporâneo}

As alterações na indústria da música, ao nível da criação, promoção e consumo, a par das transformações do mercado de trabalho, têm impacto na própria noção do que é ser músico hoje em dia. Com base no trabalho de campo realizado, detemo-nos agora naquelas que são as representações dos nossos entrevistados sobre a atual condição de músico em Portugal.

De uma forma transversal estas podem ser agrupadas em cinco categorias de análise. Uma primeira categoria prende-se com as perceções relativas à atividade musical, que acabam por assumir a forma de um conjunto de valores e de atitudes tidos como essenciais à atividade de músico. Assim, uma enorme vontade e paixão são tidas como fulcrais para a prossecução de uma carreira na música. No entender dos entrevistados só assim se torna possível ultrapassar os sacrifícios financeiros e a instabilidade subjacentes a uma tal opção, bem como as exigências de investimento que uma carreira na música pressupõe. Aliás, dedicação, abertura e flexibilidade são também apresentadas como formas de estar inerentes à atividade de um músico. Acima de tudo, uma parte dos nossos entrevistados vê a atividade musical como um emprego a tempo inteiro, com as mesmas exigências de qualquer outra profissão. Como a afirmação abaixo transcrita corrobora, são assim colocadas de parte conceções da música enquanto um hobby ou um mero entretenimento, bem como as perspetivas mais romantizadas da atividade musical.

\footnotetext{
Nós hoje em dia aplicamos um formato de emprego a tempo inteiro, mas nem toda a gente tem essa disponibilidade, mesmo financeira. Nós deixamos aquela coisa poética e romântica da inspiração. Nós apostamos no trabalho, mas para isso é preciso ter o horário livre. Felizmente nós os cinco, após vários anos de investir na música, conseguimos viver só da música. Trocámos um emprego das nove às cinco no escritório por um emprego das nove às cinco no estúdio. Gabriel, 26 anos, licenciatura, músico e designer, Lisboa.
}

Porém, e avançando para uma segunda categoria de análise relativa às perspetivas acerca da música em si mesma, deparamo-nos com dois

\footnotetext{
${ }^{208}$ Do original 'To be, or not to be, that is the question', da peça Hamlet, de William Shakespeare.
} 
posicionamentos distintos por parte dos atores da cena independente. Um grupo de entrevistados adota uma postura pragmática, e mais distante da dimensão afetiva, vendo a música como um negócio, como qualquer outro trabalho. Trata-se, essencialmente, da visão daqueles que exercem apenas atividade enquanto músicos. Não deixando de considerar toda a criatividade e prazer associados ao momento da criação, diferenciem-no do momento da execução, isto é, da produção e da promoção, que implica planeamento e estratégias bem definidas para transformar a música criada em retornos económicos. Associada a esta distinção, para grande parte dos entrevistados, o foco parece estar mais no processo do que nos resultados. Por outras palavras, centram-se no fazer música e não tanto no ser músico, definindo assim a condição de músico pela ação. Por outro lado, um outro grupo de entrevistados admite ter uma relação demasiado emocional com a música, tendo por isso muita dificuldade em encará-la como uma profissão e não querendo mesmo depender dela do ponto de vista financeiro. De um modo geral, neste último caso encontram-se os músicos que conjugam a música com outras atividades, nem sempre relacionadas com a música ou com o setor criativo. Sobretudo para estes entrevistados impõe-se a procura de um equilíbrio entre as pressões financeiras e a liberdade para manter as suas paixões criativas. Como Threadgold (2018) salienta, estes músicos enfrentam os conflitos e tensões inerentes à busca de espaço mental, temporal e económico para serem criativos e ao mesmo tempo colmatarem as necessidades do dia-a-dia, o que, por sua vez, pode criar diferentes oportunidades de compromisso com a criatividade. Também Tarassi (2018) identifica esta dualidade, defendendo que o prazer de trabalhar no setor criativo, a autonomia e a flexibilidade são, muitas vezes, contrabalançados por duras condições de trabalho, a pressão da precariedade e formas de autoexploração. Os dois excertos abaixo dão conta destes diferentes posicionamentos.

Tem a ver com as condições, com o planeamento, tem a ver com
indústria. É muito feio pensar nestes termos, mas não deixa de
ser uma realidade, sobretudo para quem quer pagar a renda ao fim
do mês. Tens de ser pragmático. São dois momentos muito distintos.
É aí que eu distingo a música independente da "música dependente".
A parte da criação musical não tem nada ver com valores, com
dinheiro. Tem a ver com a liberdade criativa e prazer criativo.
Isso é um momento. o outro momento é a promoção e a concretização
em termos económicos daquilo que tu fazes. otávio, 27 anos,
licenciatura, músico e estagiário de advocacia, Porto.
Para mim música está essencialmente ligada à emoção, àquilo que
eu sinto. Então é muito difícil pensar na música como um trabalho.
(...) E é-me difícil perceber como é que as outras pessoas podem 
fazer carreira disso. Entrar na música como uma carreira, para mim não é a maneira de a fazer. Tu entras na música como uma coisa de que tu gostas, que faz parte de ti, que acontece. Se a carreira acontecer, ótimo. E tu podes ajudar a que ela aconteça. Ser demasiado carreirista não sei se funciona, porque a música depende daquilo que provoca nas outras pessoas e tu não advinhas isso. Daniela, 37 anos, mestrado, música e ilustradora, Lisboa.

Tabela IV.3.1. Profissão dos entrevistados

\begin{tabular}{|l|c|c|}
\hline \multicolumn{1}{|c|}{ Profissão } & N.․ & \% \\
\hline Músico e... & 27 & 39 \\
\hline Apenas músico & 14 & 20 \\
\hline Promotor & 7 & 10 \\
\hline $\begin{array}{l}\text { Estudante e } \\
\text { músico }\end{array}$ & 6 & 9 \\
\hline Radialista & 4 & 6 \\
\hline Jornalista & 3 & 4 \\
\hline Programador & 3 & 4 \\
\hline Agente & 2 & 3 \\
\hline Produtor & 2 & 3 \\
\hline Editor & 1 & 1 \\
\hline $\begin{array}{l}\text { Diretor de } \\
\text { associação }\end{array}$ & 1 & 1 \\
\hline Total & 70 & 100 \\
\hline
\end{tabular}

Fonte: Elaboração da autora.
Tabela IV.3.2. Atividades desenvolvidas em paralelo com a música

\begin{tabular}{|l|c|c|}
\hline $\begin{array}{l}\text { Atividades desenvolvidas } \\
\text { em paralelo com a música }\end{array}$ & N.․- & $\%$ \\
\hline Produção & 7 & 26 \\
\hline Design & 4 & 15 \\
\hline Ensino & 3 & 11 \\
\hline Arquitetura & 2 & 7 \\
\hline Promoção & 2 & 7 \\
\hline Ilustração & 1 & 4 \\
\hline Artes visuais & 1 & 4 \\
\hline Fotografia & 1 & 4 \\
\hline Agenciamento & 1 & 4 \\
\hline Programação & 1 & 4 \\
\hline Técnico de som & 1 & 4 \\
\hline Trabalhos pontuais & 1 & 4 \\
\hline Tradução & 1 & 4 \\
\hline Advocacia & 1 & 4 \\
\hline Total & 27 & 100 \\
\hline
\end{tabular}

Fonte: Elaboração da autora.

Uma terceira categoria de análise está estreitamente relacionada com as condições de vida dos músicos. E aqui sobressaem essencialmente aspetos menos positivos. Desde logo a condição de trabalhar como freelancer, não tendo horários formais ou convencionais, e a disponibilidade para correr riscos e para viver com a imprevisibilidade. No mesmo sentido, aqueles que afirmam ser possível viver da música, dizem fazê-lo sem grandes luxos, ou seja, pagando as contas, mas vivendo em condições que classificam como modestas. Na maior parte dos casos, os nossos entrevistados dão conta da necessidade de complementar a atividade de músico com outras atividades. Mais concretamente, e como é possível comprovar através das tabelas 1 e 2, dos 59\% dos entrevistados músicos, apenas 20\% são exclusivamente músicos, enquanto 39\% afirmam conciliar a atividade enquanto músicos com outras. No que concerne às atividades desenvolvidas em paralelo com a música, o destaque vai para as atividades de produção musical e para o trabalho como designer. 
Uma quarta categoria de análise prende-se com uma comparação entre o momento atual e um passado recente (com um intervalo de 20 a 30 anos) relativamente à maior ou menor facilidade de viver e fazer carreira na música. De um modo geral, ainda que com algumas nuances, os entrevistados afirmam perentoriamente que hoje é mais fácil fazer música. Não só os instrumentos e todos os materiais se tornaram mais acessíveis, incluindo os estúdios, como todas as ferramentas digitais e a própria Internet permitiram uma democratização do processo de criação musical e também do processo de aprendizagem. Paralelamente, as redes sociais e todas a plataformas de partilha e divulgação de música (MySpace, SoundCloud, Bandacamp, Spotify, ...) possibilitam uma mais fácil e mais rápida promoção, muitas vezes, feita pelos próprios músicos. As distâncias encurtam-se e as músicas produzidas em Portugal podem ser ouvidas e adquiridas praticamente em qualquer parte do mundo. Todavia, tal faz com que a competição seja também maior. Hoje são muitas mais as pessoas a criar e a divulgar a sua música, pelo que se torna difícil um músico ou uma banda distinguir-se e sobressair numa quase infinidade da oferta musical. $E$ isso leva-nos a uma segunda dimensão desta categoria. Se por um lado é mais fácil fazer música, tal não significa necessariamente que seja mais fácil viver dela.

Uma quinta e última categoria de análise, que de certo modo agrega as anteriores, remete-nos para as perspetivas relativamente às oportunidades de construção de uma carreira na música. A este nível a perspetiva dominante é a de que hoje há mais oportunidades, uma vez que existem mais meios, mais recursos e mais redes entre os diferentes atores do campo musical. Ainda assim, os entrevistados equacionam diferentes tipos de viabilidade económica, por isso, diferentes tipos de carreira, dependendo dos géneros musicais em que os músicos se movem. Paralelamente, partilham da perceção de que ser músico ou fazer carreira na música é algo cíclico, não apenas ao longo dos vários momentos do ano, consoante os períodos com mais ou menos concertos, mas também ao longo de toda a sua trajetória, ela própria composta por altos e baixos. Como que sumariando as representações que temos vindo a apresentar, um dos entrevistados afirma mesmo ver a carreira de um músico como um trabalho cada vez mais operário e menos burguês, pela necessidade de fazer música todos os dias, por toda a quantidade de trabalho (muito dele administrativo e burocrático) associado à atividade de músico e pela necessidade de estar envolvido em tudo aquilo 
o que está relacionado com a música, o que nos leva ao que referimos no início sobre a multiplicidade de papéis assumidos pelos músicos.

\section{No multiplicar é que está o ganho ${ }^{209}$. Estratégias para a construção de carreiras na música independente em Portugal}

Após analisadas as representações sobre a condição de músico urge descortinar aquelas são as estratégias mobilizadas pelos diferentes atores para a construção e gestão das suas carreiras na música.

O segredo é multiplicar. Indo ao encontro da ideia com que terminámos o ponto anterior, a estratégia mais referida pelos nossos entrevistados (69\%) é precisamente o desempenho de diferentes papéis na música. Trata-se da materialização do ethos DIY, assegurando várias fases do processo de fazer música (criação, produção, distribuição, promoção). À dimensão criativa de escrever, compor e tocar, estes agentes adicionam muitas outras atividades - a de produtores, editores, promotores, agentes, designers (de capas de discos, cartazes de concertos), entre outras. Na maior parte dos casos, as competências necessárias à realização destas atividades são adquiridas pela prática e pelo contacto com pares. Noutros advêm do seu percurso formativo. De salientar que no âmbito desta estratégia incluímos os músicos que escrevem, compõem ou produzem para outros artistas. Com efeito, a mobilização de competências várias, o controlo dos diferentes momentos do processo e o trabalho para outros músicos (para um cliente), aproxima-nos da visão de Becker (2008 [1982]), ou mais recentemente de Perrenoud \& Bataille (2017), do trabalho do músico comparado ao trabalho de artesão, que é aliás reconhecida por um dos nossos entrevistados.

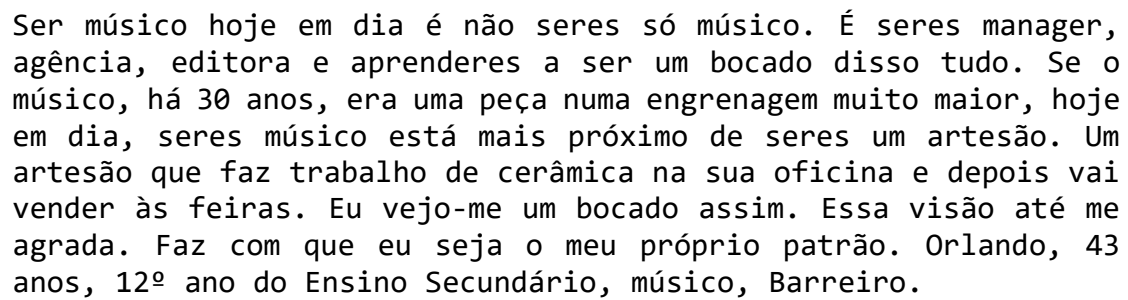

Uma segunda estratégia, referida por $54 \%$ dos entrevistados, implica conciliar a música com outra profissão. Mais concretamente pressupõe ter um day job que, muitas vezes, não está relacionado com a música. Para alguns esta é uma estratégia à qual recorrem apenas nos períodos em que a música não é suficiente para garantir a sua sustentabilidade económica. Noutros casos, este é um emprego permanente, e não raras as vezes o emprego

\footnotetext{
${ }^{209}$ Adaptação própria do ditado popular português "No poupar é que está o ganho".
} 
principal ou em pé de igualdade com a música. Em qualquer um dos casos, é essencial a flexibilidade de horários, de modo a facilitar a marcação de ensaios, concertos e tours.

A multiplicidade de projetos musicais é também uma das estratégias mais mobilizadas pelos nossos entrevistados (40\%). Incluem-se aqui os chamados músicos de sessão, que acompanham outros artistas ou que tocam noutros projetos que não da sua autoria, mas também os músicos que possuem distintos projetos autorais. Na verdade, esta estratégia é vista, por um lado, como permitindo a manifestação de diferentes identidades e linguagens artísticas e, por outro, como possibilitando tocar várias vezes nos mesmos espaços de concerto, sem repetir o projeto e assim alargando as fontes de rendimento. Ainda neste primeiro conjunto de estratégias que pressupõe exercícios de multiplicação, para $16 \%$ dos nossos entrevistados uma das estratégias é precisamente ser músico de diferentes formas. Ou seja, ser criador e autor, mas também "músico artesão", que cria música para um cliente e segundo diretivas previamente definidas. Aqui incluem-se os casos dos músicos que licenciam a sua música para outros, por exemplo compondo bandas sonoras para cinema, teatro, dança, televisão e publicidade.

Business as usual. Um segundo conjunto de estratégias associa-se a uma das conceções da música e da atividade musical que anteriormente referimos - a da música como uma qualquer outra profissão, como um negócio. Assim, e remetendo-nos para a dimensão relacional e coletiva da música (Crossley \& Bottero, 2015; Crossley, McAndrew, \& Widdop, 2014; Guerra, 2015; Mcandrew \& Everett, 2015), uma outra estratégia essencial à construção e manutenção de uma carreira na música é a promoção de redes, de relações e de contactos (referida por $23 \%$ dos entrevistados). É, assim, salientada a importância de estar associado a núcleos de artistas e de conhecer as pessoas certas, aquelas que podem gerar oportunidades. Neste sentido, os entrevistados dão relevo às relações informais estabelecidas no decorrer da frequência noturna de espaços de fruição musical e socialização. As divisões entre lazer e trabalho e entre produção e consumo esbatem-se, o que é aliás um traço característico dos circuitos de produção cultural de pequena escala.

O mesmo acontece entre vida privada e trabalho, sendo que qualquer ocasião social pode transformar-se numa oportunidade profissional. Também Tarassi (2018) dá conta da importância da inserção em redes e da aquisição de capital relacional e social, capaz de criar um sistema de confiança e 
reputação. Estas redes funcionam como plataformas de aquisição de competências e conhecimentos essenciais ao desempenhar dos vários papéis que uma carreira na música pressupõe, para além de poderem promover novas oportunidades de trabalho, na medida em que tendem a ser usadas como principal canal de recrutamento de novo talento e de procura de novos empregos. Porém, importa ressalvar que redes demasiado fechadas e homofílicas podem mais ou menos conscientemente bloquear a entrada de novos membros, como que criando uma espécie de pequenos lobbies e, inevitavelmente, tensões entre quem está dentro e fora da rede.

Uma outra estratégia neste conjunto, referida por $19 \%$ dos entrevistados, passa pela necessidade de planear a carreira, definindo uma estratégia e uma metodologia de trabalho. Assume aqui importância uma dimensão racional e metódica da música por oposição à visão romântica e boémia dos músicos. Incluímos também neste conjunto de estratégias o recurso aos direitos de autor, que é identificado como uma estratégia relevante também por $19 \%$ dos entrevistados. Tal implica ser associado da Sociedade Portuguesa de Autores (SPA), cuja atuação é vista por grande parte dos entrevistados de forma negativa. Porém, alguns deles afirmam ser uma cedência que fazem (entrar num jogo com cujas regras de funcionamento não concordam) para ampliar as suas fontes de rendimento. $O$ excerto seguinte denota bem esta tensão:

\begin{abstract}
Há dois tipos de músicos em Portugal. Há os gajos que estão ligados à SPA e sabem tudo. Depois há o pessoal que tem uma atitude contra. E eu tive durante alguns anos e perdi imenso dinheiro à custa disso. Descobri anos mais tarde a quantidade de dinheiro que tinha perdido por ter tido este tipo de atitude e que eles ganharam. É que este dinheiro depois vai para sítios que nem sabes para onde vai. Leopoldo, 36 anos, licenciatura, músico e agente, Porto.
\end{abstract}

Criar, partilhar, não parar. Num último conjunto de estratégias incluímos as atuações ao vivo e a realização de um circuito de concertos. Com a quebra na venda de discos registada a nível mundial, a música ao vivo tornou-se uma importantíssima fonte de rendimento dos músicos. $20 \%$ dos entrevistados refere que tocar tantas vezes quanto possível é uma estratégia essencial. O mesmo acontece com a ideia de manter uma atividade contínua, nunca parando. Isto é, uma das estratégias (referida por $16 \%$ dos entrevistados) passa por garantir a continuidade do ciclo criativo, estando sempre envolvido em algum dos momentos do processo, seja a compor, a gravar, a produzir, a editar ou a tocar. No mesmo sentido, é igualmente mencionada (por 13\% dos entrevistados) a importância de fazer álbuns com 
regularidade, de modo a potenciar um maior número de concertos e também para que público e os media não se esqueçam do músico ou da banda.

\section{Faça música você mesmo! Representações sobre o ethos e a praxis DIY}

Focamo-nos agora nas representações sobre a presença do ethos e da praxis DIY nas carreiras dos atores da cena independente. Desde logo, e antes de mais, o DIY surge como uma necessidade, sobretudo premente na cena independente e, em especial, nos momentos iniciais das trajetórias musicais e também no caso de músicos mais velhos, que iniciaram o seu percurso num contexto em que o acesso a estúdios de gravação e à edição de álbuns ou EPs era bem mais limitado, sendo dominado pelas grandes editoras. À semelhança do que Paula Guerra (2018) evidencia no âmbito da cena punk portuguesa, o DIY surge aqui como alternativa à escassez de recursos, ou à falta de acesso a eles, e como uma forma de poupar dinheiro, facilitando investimentos futuros. Assim o descreve um dos nossos entrevistados.

\footnotetext{
Começou por ser uma necessidade, porque comecei a fazer coisas nessa altura de transição, em que era muito difícil. Era gravadores de pista na garagem, gravar cassetes, tirar fotocópias das maquetes das cassetes, ir entregar à rádio local. Isso é o DIY, o único possível na altura, era a única maneira de fazer coisas se não tivesses um contrato com uma editora discográfica. orlando, 43 anos, ensino secundário, músico, Barreiro.
}

De formas mais ou menos assumidas, o DIY é também entendido como uma afirmação, como um statement. Assumir uma tal postura é um modo de assegurar a independência, a autonomia, a liberdade criativa para fazer a música que querem e da forma que pretendem, acabando por gerar uma alternativa ao tradicional funcionamento da indústria musical. Paralelamente, serem os próprios músicos a executar diferentes tarefas permite-lhes um maior controlo de todas as dimensões e fases do processo de criação e divulgação musical. Com efeito, alguns dos nossos entrevistados associam à atitude DIY um sentimento de orgulho em relação àquilo que são capazes de fazer com os seus próprios meios. Indo ao encontro da génese do movimento punk, os atuais protagonistas da cena independente portuguesa descrevem os seus percursos e projetos como tratando-se também do preenchimento de lacunas previamente identificadas. Pense-se no exemplo dos promotores de concertos. Muitos admitem ter iniciado essa atividade devido à ausência de oferta de concertos das bandas de que gostavam e queriam ver na sua cidade. O DIY surge aqui associado a uma lógica de ação e de criação de possibilidades. 
É tentares ser autónomo. Principalmente na música independente (e acho que hoje em dia quase toda a gente começa de forma independente) acho que o ideal é tu fazeres tudo o que puderes que está relacionado com a tua atividade enquanto músico. 0 que não sabes deves procurar saber ou arranjar quem te ensine, ou quem te aconselhe. Mas deves sempre procurar que parta de ti a procura de saber como é. Osvaldo, 26 anos, a completar o mestrado, estudante, músico e promotor, Porto.

Finalmente, é evidente no discurso dos nossos entrevistados a justificação e legitimação da presença do DIY no modo como gerem as suas carreiras através do prazer que tal Ihes proporciona. Assim, muitos afirmam que sempre gostaram, interessaram e tiveram vontade de aprender diferentes tarefas, fases ou áreas relacionadas com a música. Daí ao desempenhar de diferentes papéis do processo musical foi um percurso que, nas suas palavras, surgiu como sendo natural. Esta associação discursiva ao gosto pessoal por este modo de fazer leva-nos a questionar até que ponto estas lógicas de ação, elas próprias definidoras do que é ser independente, estão enraizadas no quotidiano destes atores.

\section{Conclusão}

Chegados aqui, e tentando responder às questões colocadas no início, importa tecer algumas considerações finais. Desde logo, a de que existem diferentes formas de ser músico e de estar na música e, por isso, diferentes tipos de carreiras. As diferenciações definem-se pelas perspetivas em relação à música, através da adoção de uma postura mais pragmática, estratégica e metódica, ou privilegiando uma ligação mais emocional à música. Definem-se também pelas estratégias adotadas pelos atores para a gestão da sua carreira e, igualmente, pelo papel desempenhado na cena. Neste sentido, parece haver uma mais fácil profissionalização de outras atividades em torno da música que não a atividade de músico (por exemplo, trabalho na área da produção, promoção, agenciamento, crítica/jornalismo musical), existindo, por isso, diferentes níveis de viabilidade de uma carreira na música.

Simultaneamente, é possível concluir que sobretudo os músicos mais jovens têm dificuldade em ver a música como uma profissão e como a única profissão. Por um lado, porque não acreditam ser possível viver exclusivamente dela. Por outro, porque têm vontade de se expressar através de outras linguagens artísticas. Não se veem limitados a um único canal de expressão, pelo que a música é apenas uma das possibilidades através da qual podem dar aso à sua criatividade e à qual podem voltar sempre que 
desejarem. Nestes casos a carreira na música é composta por uma sequência de movimentos de avanço e recuo em relação à atividade musical.

Uma terceira nota é a de que ser músico é, em primeiro lugar e acima de tudo, não ser apenas músico, é fazer um trabalho de artesão. Ser músico pressupõe várias formas de multiplicação. Implica antes de mais multiplicidade de papéis e envolvimento nos diferentes momentos do processo criativo, que assume enorme preponderância no rol de estratégias mobilizadas para a gestão de carreiras musicais na cena independente. $\mathrm{Na}$ verdade, este pode ser visto como um elemento-chave na definição da atual condição de músico. Esta multiplicidade é, no entanto, geradora de tensões. À visão emocional da música opõe-se uma leitura da música enquanto negócio, que tem de ter retorno económico. Ao trabalho criativo opõe-se o trabalho administrativo, disputando o tempo, a concentração e a dedicação dos músicos. À carreira musical opõe-se, muitas vezes, um day job, com todas as limitações que o segundo impõe à primeira.

Quanto à presença do DIY, é desde logo evidente que a Internet, em todas as suas vertentes, é um elemento facilitador, gerando grandes impactos na construção e gestão de carreiras na música, tanto do ponto de vista da criação e promoção musical, como ao nível da aprendizagem, não só da música em si, mas também de todas as atividades a ela associadas. Paralelamente, o DIY parece surgir quase como uma obrigação, como um requisito para a construção de uma carreira na música independente. Por um lado, discursivamente, não deixa de aparecer conotado com a vontade de afirmar um posicionamento, aproximando-se da noção do DIY aquando da génese do movimento punk, e adotando um caráter ideológico e de resistência. Por outro, e em simultâneo, o DIY adquire no caso dos nossos entrevistados um caráter iminentemente pragmático, surgindo como necessidade e enquanto estratégia de sobrevivência na música. Não deixando de assentar na independência e liberdade criativas, é intersetado pelo reconhecimento da necessidade de garantir um estilo de vida sustentável. Tal pressupõe diferentes formas de independência, consoante 0 maior ou menor envolvimento nas lógias da indústria musical e que nem sempre vão ao encontro da autenticidade DIY. Como defende Tarassi (2018), a estrutura binária que opõe bandas que assinam por uma major e bandas que se recusam a tal, de modo a preservar a sua ética DIY, não mais oferece uma descrição profícua das estratégias mobilizadas pelas bandas independentes para conseguirem viver da música. Alguns (Jian, 2018; 
Threadgold, 2018) falam de uma cooptação do conceito DIY, na medida em que o ethos associado facilmente ressoa na ideologia neoliberal (o discurso do empreendedorismo, a valorização do indivíduo e das suas capacidades), esbatendo-se o potencial subversivo e de resistência. Nós argumentamos no sentido da transformação e redefinição da noção de carreiras DIY, assente na existência de interseções várias entre esferas que antes se opunham: independente e comercial, arte e comércio, trabalho e lazer, ideologia e pragmatismo.

\section{Referências Bibliográficas}

Abreu, P., Silva, A. S., Guerra, P., Oliveira, A. \& Moreira, T. (2017). The social place of the Portuguese punk scene: an itinerary of the social profiles of its protogonists. Volume!, 14(1), pp. 103-126.

Almeida, J. F. de, Costa, A. F. da, \& Machado, F. L. (1990). Estudantes e amigos trajectórias e redes de sociabilidade. Análise Social, XXV105-106), pp. 193-221.

Almeida, J. F. de, Costa, A. F. da, \& Machado, F. L. (1988). Famílias, estudantes e universidade: painéis de observação sociográfica. Sociologia - Problemas e Práticas, n. ${ }^{4}$, pp. $11-44$.

Beck, U. (1992). The risk society: towards a new modernity. London: Sage.

Becker, H. (1982). Art Worlds. Berkeley and Los Angels: University of California Press.

Bennett, A. (2018). Conceptualising the relationship between youth, music and DIY careers: a critical overview. Cultural Sociology, 12(2), pp. 140-155.

Bennett, A. \& Guerra, P. (2019) (Eds.). DIY cultures and underground music scenes. Abingdon/New York: Routledge.

Bertaux, D. (1997). Les récits de vie. Paris: Nathan University.

Bourdieu, P. (1993). The field of cultural production: essays on art and literature. New York: Columbia University Press.

Campbell, M. (2013). Out of the basement. Youth cultural production in practice and in police. Montreal: McGill-Queen's University Press.

Crossley, N., \& Bottero, W. (2015). Social Spaces of Music: Introduction Background. Cultural Sociology, 9(1), pp. 3-19..

Crossley, N., McAndrew, S., \& Widdop, P. (Eds.) (2014). Social Networks and Music Worlds. London: Routledge.

Dale, P. (2008). It was easy, it was cheap, so what?: reconsidering the DIY principle of punk and indie music. Popular Music History, 3(2), pp. 171-193.

Dale, P. (2010). Anyone Can Do It: traditions of punk and the politics of empowerment. 
Newcastle: Newcastle University.

Debord, G. (1967). La société du spectacle. Paris: Buchet/Chastel.

Glaser, B., \& Strauss, A. (1967). The discovery of grounded theory: strategies for qualitative research. New York: Aldine.

Guerra, P. (2013). A Instável Leveza do Rock: génese, dinâmica e consolidação do rock alternativo em Portugal (1980-2010). Porto: Edições Afrontamento.

Guerra, P. (Org.) (2015). More than loud. Os mundos dentro de cada som. Porto: Edições Afrontamento.

Guerra, P. (2017). 'Just can't go to sleep': DIY cultures and alternative economies from the perspective of social theory. Portuguese Journal of Social Science, 16(3), pp. 283303.

Guerra, P. (2018). Raw power: punk, DIY and underground cultures as spaces os resistance in contemporary Portugal. Cultural Sociology, 12(2), pp. 241-259.

Haenfler, R. (2018). The entrepreneurial (straight) edge: how participation in DIY music cultures translates to work and careers. Cultural Sociology, 12(2), pp. 174-192.

Hein, F. (2012). Le DIY comme dynamique contre-culturelle? L'exemple de la scéne punk rock. Volume!, 9(1), pp. 105-126.

Hennion, A., Maisonneuve, S., \& Gomart, E. (2000). Figures de l'Amateur: formes, objets, pratiques de l'aniour de la musique aujourd'hui. Paris: La Documentation Française.

Instituto Nacional de Estatística. (2011). Classificação portuguesa das profissões. Lisboa: Instituto Nacional de Estatística.

Jian, M. (2018). The survival struggle and resistant politics of a DIY music career in East Asia: case studies of China and Taiwan. Cultural Sociology, 12(2), pp. 224-240.

Laing, D. (1985). One Chord Wonders: Power and Meaning in Punk Rock. Philadelphia: Open University Press.

Leadbeater, C. \& Oakley, K. (1999). The Independents: Britain's new cultural entrepreneur. London: Demos.

Mcandrew, S. \& Everett, M. (2015). Music as Collective Invention: A Social Network Analysis of Composers. Cultural Sociology, 9(1), pp. 56-80.

McKay, G. (1998). DiY Culture: notes towards an intro. DiY Culture: Party and Protest in Nineties Britain, pp. 1-53.

McRobbie, A. (1999). In the Culture Society: Art, Fashion and Popular Music. London \& New York: Routledge.

McRobbie, A. (2004). Making a living in London's small-scale creative sector. In Dominic Power and Allen J. Scott (Eds.), Culture Industries and the Production of 
Culture. New York: Routledge.

McRobbie, A. (2016). Be creative: making a living in the new culture industries. Cambridge: Polity Press.

Moran, I. (2010). Punk: The Do-It-Yourself Subculture. Social Sciences Journal, 10(1), pp. 58-65.

Oliver, P. (2010). The DIY artist: issues of sustainability within local music scenes. Management Decision, 48(9), pp. 1422-1432.

Perrenaud, M., \& Bataille, P. (2017). Artist, craftsman, teacher: "being a musician" in France and Switzerland. Popular Music and Society. https://doi.org/DOI: 10.1080/03007766.2017.1348666

Plant, S. (2002). The most radical gesture: the Situationist International in a postmodern age. London \& New York: Routledge.

Reitsamer, R., \& Prokop, R. (2018). Keepin' it real in Central Europe: the DIY rap music careers of male hip hop artists in Austria. Cultural Sociology, 12(2), pp. 193-207.

Reitsamer, R. (2011). The DIY careers of techno and drum " $n$ " bass DJs in Vienna. Journal of Electronic Dance Music Culture, 3(1), 28-43.

Standing, G. (2011). The Precariat: the new dangerous class. London: Bloomsbury Academic.

Tarassi, S. (2011). Independent to What? An Analysis of The Live Music Scene in Milan. Universita' Cattolica del Sacro Cuore Milano.

Tarassi, S. (2018). Multi-tasking and making a living from music: investigating music careers in the independent music scene of Milan. Cultural Sociology, 12(2), p. 208-223.

Threadgold, S. (2018). Creativity, precarity and illusio: DIY cultures and "choosing peverty." Cultural Sociology, 12(2), 156-173.

UNESCO, Institute for Statistics (2012). International Standard Classification of Education - ISCED 2011. Canada: UNESCO Publications. 